\title{
Mechanisms of Accelerated Liver Fibrosis Progression during HIV Infection
}

\author{
Jose D. Debes* ${ }^{1}$, Paul R. Bohjanen ${ }^{1}$ and Andre Boonstra ${ }^{2}$ \\ ${ }^{1}$ Department of Medicine, Division of Infectious Disease and International Medicine, University of Minnesota, \\ Minneapolis, MN, USA; ${ }^{2}$ Department of Gastroenterology and Hepatology, Erasmus MC, Rotterdam, The Netherlands
}

\begin{abstract}
With the introduction of antiretroviral therapy (ART), a dramatic reduction in HIV-related morbidity and mortality has been observed. However, it is now becoming increasingly clear that liver-related complications, particularly rapid fibrosis development from ART as well as from the chronic HIV infection itself, are of serious concern to HIV patients. The pathophysiology of liver fibrosis in patients with HIV is a multifactorial process whereby persistent viral replication, and bacterial translocation lead to chronic immune activation and inflammation, which ART is unable to fully suppress, promoting production of fibrinogenic mediators and fibrosis. In addition, mitochondrial toxicity, triggered by both ART and HIV, contributes to intrahepatic damage, which is even more severe in patients co-infected with viral hepatitis. In recent years, new insights into the mechanisms of accelerated fibrosis and liver disease progression in HIV has been obtained, and these are detailed and discussed in this review. (C) 2016 The Second Affiliated Hospital of Chongqing Medical University. Published by XIA \& HE Publishing Inc. All rights reserved.
\end{abstract}

\section{Introduction}

Liver disease is a major cause of morbidity and the main cause of mortality, independent of acquired immunodeficiency syndrome (AIDS), in persons infected with the human immunodeficiency virus (HIV), with liver fibrosis being a highly significant contributor. ${ }^{1}$ Although HIV co-infection with hepatitis $B$ virus ( $\mathrm{HBV}$ ) or hepatitis $\mathrm{C}$ virus (HCV) is frequent, there is mounting evidence of an increased risk in liver-related morbidity and mortality in the absence of viral hepatitis. ${ }^{2,3}$ Cross-sec-

Keywords: HIV; Liver fibrosis; Mitochondrial toxicity; Bacterial translocation. Abbreviations: HBV, hepatitis B virus; $\mathrm{HCV}$, hepatitis C virus; AIDS, acquired immunodeficiency virus; LSM, liver stiffness measurement; HSC, hepatic stellate cell; ROS, reactive oxygen species; ART, antiretroviral therapy; NAFLD, nonalcoholic fatty liver disease; HALS, HIV-associated lipodystrophy syndrome; CTGF, connective tissue growth factor; MCP-1, chemokine monocyte chemoattractant protein 1; TIMP, tissue inhibitor metalloproteinases; TRAIL, TNF-related apoptosis inducing ligand receptor; TGF- $\beta$, tumor growth factor-beta; LPS, lipopolysaccharide; NK, natural killer; NRTI, nucleoside reverse transcriptase inhibitor; d4T, stavudine; AZT, Zidovudine; DAA, direct acting antiviral.

Received: 30 August 2016; Revised: 14 October 2016; Accepted: 21 October 2016

DOI: $10.14218 /$ JCTH.2016.00034.

* Correspondence to: Jose D. Debes, Department of Medicine, Division of Infectious Disease and International Medicine, University of Minnesota, 20016 th Street SE, Minneapolis, MN 55455, USA. Tel: +1-612-624-6353, Fax: +1-612-3011292, E-mail: debes003@umn.edu tional studies using liver stiffness measurement (LSM) by transient elastography have shown a significant degree of fibrosis among HIV patients, from $17 \%$ in one study to a staggering $41 \%$ in a recent study that used lower cutoff values of LSM, although both studies involved patients without viral hepatitis. ${ }^{4,5}$ Moreover, liver fibrosis progression is accelerated during $\mathrm{HIV}$ and HCV co-infection. An analysis using paired liver biopsies showed progression of at least one fibrosis stage (METAVIR) in $34 \%$ of HIV/HCV co-infected individuals over a 2.5-year period. ${ }^{6}$

Hepatic fibrosis is a dynamic process initiated by liver injury that results in increased deposition of extracellular matrix proteins in the space of Disse, the area in between the hepatocytes and the liver sinusoids, which is mainly inhabited by hepatic stellate cells (HSCs). ${ }^{7,8}$ Accumulation of extracellular matrix proteins and their decreased removal by matrix metalloproteinases results in a progressive replacement of the liver parenchyma by scar tissue, leading to liver fibrosis and its complications. ${ }^{9}$ Activation of HSCs is a key event in the process leading to excessive deposition of extracellular matrix proteins and the subsequent fibrosis. This activation of HSCs is triggered by numerous events, such as the release of cellular components by injured hepatocytes, lipid accumulation, the secretion of reactive oxygen species (ROS) produced by macrophages, and exposure to cytokines produced by intrahepatic macrophages, lymphocytes and endothelial cells. ${ }^{10}$ In this review, we summarize and comment on the different potential mechanisms and multiple factors related to liver fibrosis during $\mathrm{HIV}$ infection (Fig. 1). These include: the effects of antiretroviral therapy (ART), persistent HIV infection-induced immune activation, inflammation due to bacterial translocation from the gastrointestinal tract into the portal circulation, and insulin resistance. We also describe mechanisms related to co-infection with viral hepatitis, but we have not extended on this topic since there are multiple comprehensive reviews about this subject in the literature. ${ }^{11,12}$

Our search strategy included search of the PubMed database from 1980 until 2016. We used multiple search terms, including: HIV, liver fibrosis, inflammation, mitochondrial oxidation, etc. We included primarily research articles, as well as review articles for general relevant and not controversial data.

\section{Metabolic dysfunction during HIV infection}

Prior to the availability of effective ART, patients with HIV infection exhibit progressive impairment of their immune systems, leading to AIDS and death. With effective ART, the development of AIDS can be prevented and people with HIV 
Debes J.D. et al: Liver fibrosis in HIV

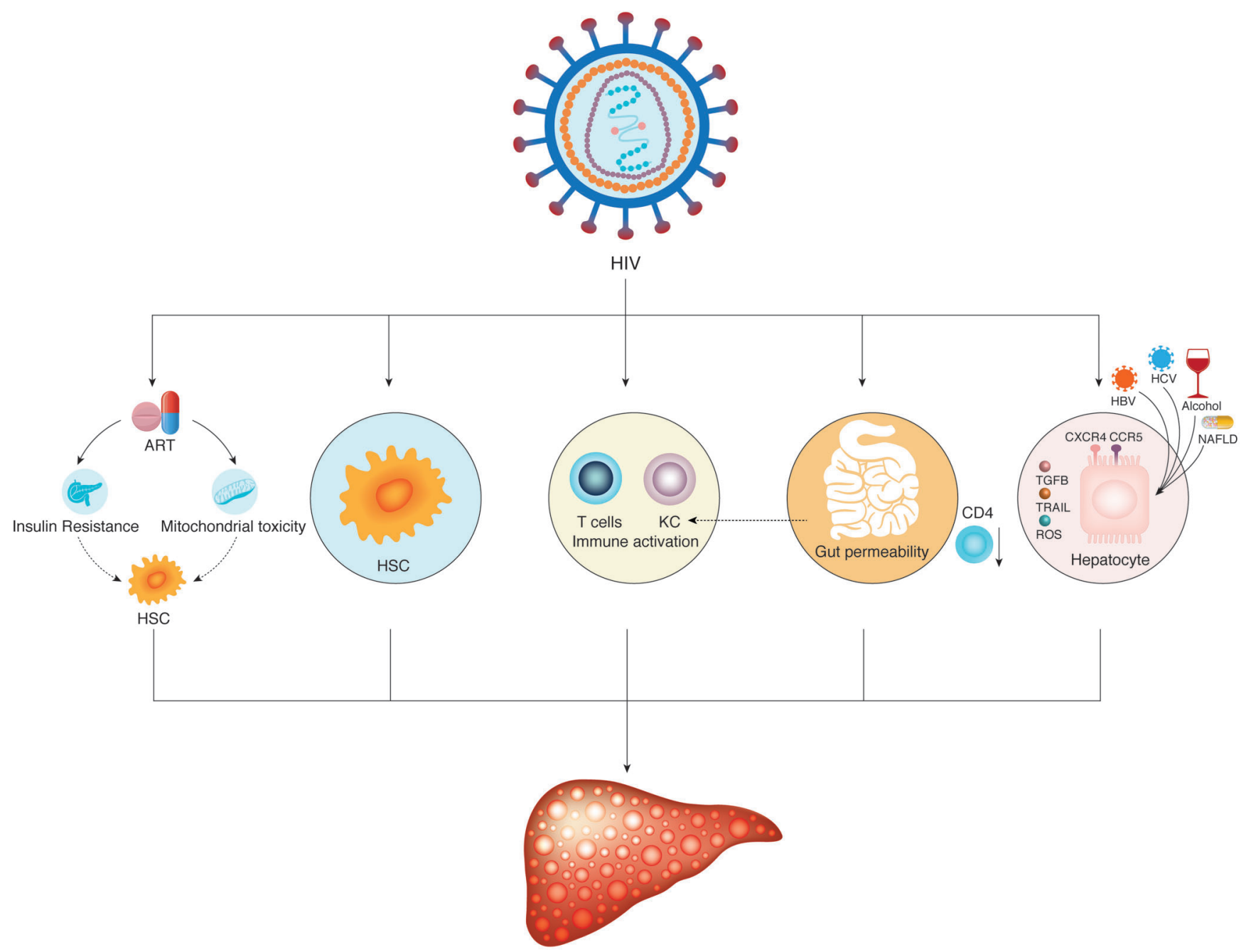

Liver Fibrosis

Fig. 1. Factors affecting liver fibrosis during human immunodeficiency virus (HIV) infection. HIV can induce a direct effect on hepatic stellate cells (HSCs), affect T cells and Kupffer cells (KCs), affect hepatocytes through co-receptors, such as CCR5 and CXCR4, and affect mitochondrial DNA. HIV can also increase gut permeability through depletion of intestinal $\mathrm{CD}^{+}$cells, increasing bacterial translocation. Antiretroviral therapy (ART) can induce insulin resistance and mitochondrial toxicity in the liver. Other factors like hepatitis B (HBV), hepatitis C (HCV) and alcohol consumption can affect hepatocytes' worsening liver fibrosis.

infection on successful ART have almost the same life expectancy as HIV-uninfected persons (although in countries such as the United States, these elite responders to ART represent less than $50 \%$ of the HIV population). ${ }^{13}$ As HIV-infected patients age, they develop increased abdominal obesity and exhibit an increased incidence of non-alcoholic fatty liver disease (NAFLD), with $30-40 \%$ of HIV-infected patients showing evidence of NAFLD versus $15-20 \%$ of HIV-uninfected individuals. ${ }^{14,15}$ Moreover, a recent study shows that HIVpositive individuals with NAFLD have almost double the rates of steatohepatitis (lobular inflammation and elevated levels of aspartate aminotransferase/alanine aminotransferase) compared to age/sex-matched HIV-negative controls. ${ }^{16}$

Since excessive lipid accumulation in the liver leads to HSC activation, NAFLD and steatohepatitis enhance the risk of developing liver fibrosis. A study in a Canadian population showed that the mean BMI among HIV-infected patients with liver histology compatible with NAFLD was 26 , compared to a mean BMI of 30 among non-infected patients, suggesting that
HIV patients have a lower threshold for developing fatty infiltration of the liver. ${ }^{17} \mathrm{~A}$ cross-sectional study examining hepatic steatosis in HIV patients receiving ART suggested that certain medications included in ART represented independent risk factors for NAFLD and subsequent fibrosis development. ${ }^{18}$ However, that study analyzed patients that were already on treatment and did not prospectively address the effect of ART treatment itself on NAFLD.

A recent study by our group that evaluated Hispanics with HIV before starting ART found that $66 \%$ of HIV-infected subjects had some degree of fatty liver. ${ }^{19}$ In addition, HIV patients can present with HIV-associated lipodystrophy syndrome (HALS). HALS is associated with increased fatty acid deposition in hepatocytes secondary to elevated adiponectin levels associated to lipodystrophy. Also, HALS can lead to insulin resistance, with an increase in plasma glucose. ${ }^{20} \mathrm{High}$ levels of insulin and glucose eventually stimulate HSC proliferation and increase expression of connective tissue growth factor (CTGF) which promotes liver fibrosis progression. ${ }^{21,22}$ 
Although the mechanisms are not entirely clear, it seems evident that HIV patients present higher degrees of fat infiltration in the liver in a BMI-related or -unrelated manner, which worsens the direct and immune-related effects of the virus in liver fibrosis.

\section{Role of persistent HIV replication and chronic} immune activation

Although ART blocks HIV replication, this effect is not complete and persistent viral replication occurs, even in cases of effective ART outcome. ${ }^{23,24}$ HIV does not replicate in hepatocytes, but the HIV co-receptors CXCR4 and CCR5 are expressed on the hepatocyte surface, and the HIV protein gp120 can induce cell signaling in the liver through these co-receptors. ${ }^{25,26}$ In hepatocytes, signals triggered through activation of CXCR4 and CCR5 increase expression of procollagen alpha-1, a component of type I collagen found in the extracellular matrix that is characteristic of advanced fibrosis. Although the studies that yielded these findings were performed using hepatic cell lines, it is likely that such effects translate to physiologic conditions and contribute to liver fibrosis. ${ }^{27}$

In contrast to hepatocytes, HIV directly infects HSCs, and this infection has been shown to promote HSC collagen I expression and secretion of the proinflammatory chemokine monocyte chemoattractant protein-1 (MCP-1). ${ }^{28,29}$ The HIV gp120 protein also induces activation of tissue-inhibitor metalloproteinase (TIMP). The two proteins, MCP-1 and TIMP, are important for chemotaxis of leukocytes, and these mediators promote liver inflammation and fibrogenesis. ${ }^{28,30} \mathrm{HIV}$ renders hepatocytes sensitive to the TNF-related apoptosis-inducing ligand receptor (TRAIL), which can lead to hepatocyte death and subsequent liver fibrosis. ${ }^{31,32}$ HIV can also infect liver macrophages, known as Kupffer cells. ${ }^{11,33}$ Although the consequences of HIV expression in Kupffer cells remain unclear, these cells are known to play a key role in hepatocyte apoptosis and to be involved in the induction of steatosis. ${ }^{34}$ Moreover, a recent study showed that HIV-infected macrophage/monocytic cells secrete high levels of tumor growth factor- $\beta$ (TGF$\beta)$, which in turn activates HSC to promote fibrosis. ${ }^{35}$

Interestingly, HIV infection leads to a decreased level of IL-17-producing $\mathrm{CD} 4^{+}$T cells, a subset of $\mathrm{CD} 4^{+}$cells involved in liver fibrosis and modulation of HSCs. ${ }^{36}$ Moreover, the intrahepatic compartment in patients with chronic HCV contains more IL-17-expressing T cells, and neutrophils represent an important source of IL-17 in the human liver, particularly in late fibrosis stages. ${ }^{37,38}$ The interaction between HIV and $\mathrm{IL}-17$ likely plays a role during liver fibrosis, but yet no direct correlation between HIV, IL-17 and liver fibrosis has been exposed.

HIV-specific T cells may also play roles in promoting liver fibrosis, but evaluating intrahepatic virus-specific $T$ cell responses is difficult due to the low frequency of these cells in the liver and limited availability of liver biopsy material from patients. ${ }^{39}$ A study performed in HIV/HCV co-infected patients demonstrated the presence of both HCV-specific and HIV-specific $\mathrm{T}$ cells in the liver. ${ }^{40}$ Interestingly, that study also showed that HIV-specific T cells were more functional than the HCV-specific T cells, and therefore more well equipped to promote HSC activation.

Thus, persistent HIV infection can promote inflammatory processes in the liver that may stimulate the development of fibrosis. The specific interactions of HIV with Kupffer cells, as well as intrahepatic T cell alterations in HIV, deserve further research to better understand their role and potential therapeutic targeting for liver fibrosis.

\section{Microbial translocation and inflammation during HIV infection}

In the last decade it has become increasingly clear that microbial translocation is an important determinant of clinical manifestations and disease progression of HIV. ${ }^{41}$ Damage to the intestinal mucosa in patients with HIV leads to disruption of the gut epithelial barrier, facilitating leakage of microbial products from the gastrointestinal tract, with bacterial translocation into the portal and systemic circulation. ${ }^{42}$ This is thought to be the consequence of virus-induced depletion of $\mathrm{CD}^{+}{ }^{+}$T cells in the gut and exhaustion of the intestinal macrophage phagocytic function, both of which lead to enterocyte apoptosis and disruption of tight junctions with loss of integrity of the gut mucosa. ${ }^{43,44}$

Increased microbial translocation results in elevated circulating levels of lipopolysaccharide (LPS), LPS-binding protein, soluble CD14 and other mediators, which remain elevated during effective ART. ${ }^{41,45}$ When bacterial translocation occurs, Kupffer cells in the liver become activated through toll-like receptor (TLR) 4 and other pathogen recognition receptors acting as the first line of defense by clearing bacteria from the liver through phagocytosis. In this process, Kupffer cells are induced to produce cytokines, such as tumor necrosis factor (TNF), interleukin (IL)-1 and IL-6, which are pro-inflammatory mediators that promote liver fibrosis by directly activating HSCs or by priming and recruiting other leukocyte populations. ${ }^{46,47}$ Similar to infection of $\mathrm{CD}^{+}{ }^{+} \mathrm{T}$ cells, HIV can also directly infect Kupffer cells and promote release of profibrotic mediators. ${ }^{48}$ However, one study reported that HIV reduces the number of Kupffer cells in the liver via unknown mechanisms. ${ }^{49}$ This HIV-induced loss of Kupffer cells could limit the ability of these cells to directly activate HSCs, but likely leads to higher levels of circulating microbial products, which in turn can affect immune responses, promoting inflammation.

One of the most well-known pro-fibrogenic mediators is TGF- $\beta$, which is produced by Kupffer cells in response to TLR ligation upon exposure to microbial compounds. ${ }^{50}$ Indeed, many studies have reported a positive correlation between liver fibrosis and serum TGF- $\beta$ concentrations, intrahepatic TGF- $\beta$ mRNA levels as well as strong immunohistochemical staining for TGF- $\beta$ in liver tissue. ${ }^{51,52}$ TGF- $\beta$ directly activates HSC to promote fibrosis, but also plays a homeostatic role to prevent excessive damage by potently suppressing the function of natural killer (NK) cells and Tcells, leading to decreased hepatocyte apoptosis and release of HSC-activating mediators. ${ }^{53}$ Studies showing a clear impact of bacterial translocation on liver fibrosis have been performed in HIV/HCV co-infected patients. ${ }^{54} \mathrm{~A}$ recent study in HIV mono-infected individuals showed increased levels of soluble CD14 correlating with fibrosis, suggesting activation of monocytes in response to translocation; however, more studies are necessary to further clarify this concept. ${ }^{5}$

\section{Mitochondrial dysfunction and toxicity}

HIV itself can induce mitochondrial toxicity. Studies have shown that ART-naïve patients exhibit depletion of mitochondrial DNA in $\mathrm{CD}^{+}$as well as $\mathrm{B}$ cells, and in $\mathrm{CD} 4^{+}$cells to a 
lesser extent (Fig. 2). ${ }^{55,56}$ Because these lymphocyte subsets are known to be hyperactivated in persons with chronic HIV infection, it is possible that persistent activation and high cell turnover causes mitochondrial DNA loss. This mitochondrial dysfunction can induce apoptosis in $\mathrm{CD}^{+}$and $\mathrm{CD} 8^{+}$cells and contribute to fat accumulation in the liver with eventual fibrosis. ${ }^{56,57}$ Abnormal mitochondrial function induces the production of ROS, which induces oxidative stress with liver injury and decreases beta-oxidation of fatty acids, leading to accumulation of fat in the cytosol. ${ }^{58}$ These events are key triggers of NAFLD and steatohepatitis that will lead to the development of liver fibrosis in this setting. ${ }^{58,59}$

Interestingly, adipose tissue of untreated HIV-infected patients shows an increase in mitochondrial DNA content. ${ }^{55}$

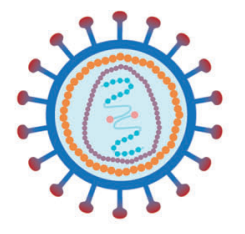

HIV

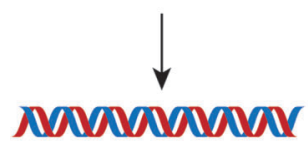

DNA in CD4/8+ $\downarrow \downarrow \downarrow$
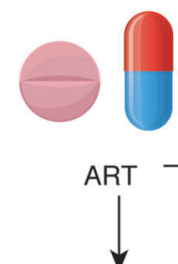

Pol-gamma $\downarrow \downarrow \downarrow$

Acetylate-kinase $\downarrow \downarrow \downarrow$

RNA polymerase $\downarrow \downarrow \downarrow$

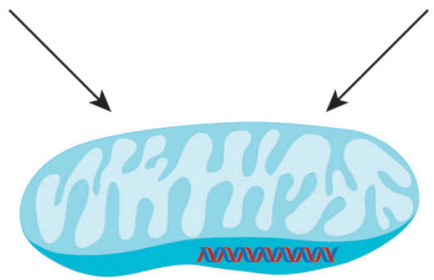

Mitochondiral DNA

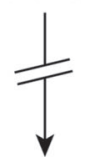

Fatty acid oxidation

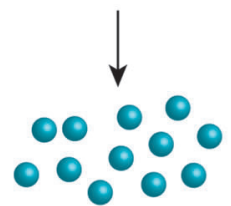

Fatty acid $\uparrow \uparrow \uparrow$
Lipolysis $\downarrow$

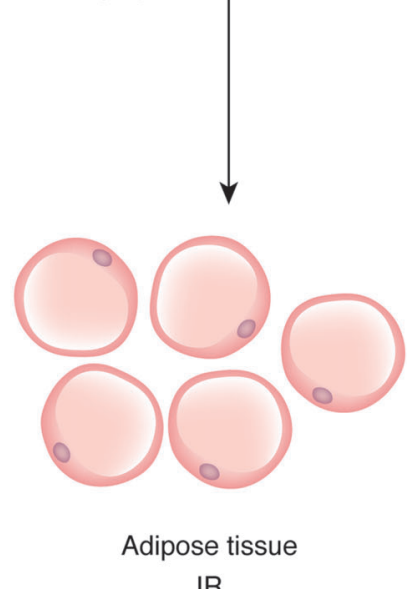

IR

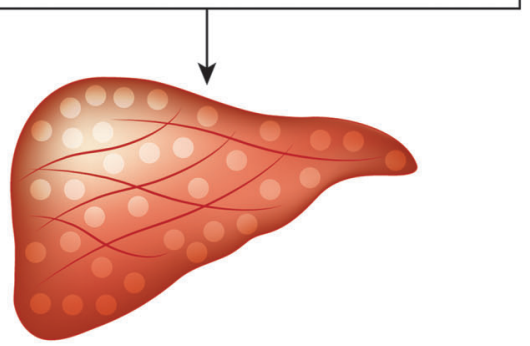

Steatosis and fibrosis

Fig. 2. Effects of human immunodeficiency virus (HIV) and antiretroviral therapy (ART) on mitochondrial toxicity. HIV virus can decrease mitochondrial DNA in $\mathrm{CD}^{+}$and $\mathrm{CD}^{+}$T cells. Different ART components can inhibit pol-gamma, acetylate kinase and RNA polymerase related to mitochondria, thereby inhibiting mitochondrial DNA. Decrease in mitochondrial DNA leads to less mitochondria and less beta-oxidation of fatty acids, with an increase in free fatty acids and their deposition in liver parenchyma leading to steatosis. Fat also accumulates in peripheral tissues augmenting insulin resistance (IR), which can also be affected by ART (through inhibition of lipolysis), all of which contributes to steatosis and liver fibrosis. 
This could represent a compensatory mechanism to counteract HIV-directed mitochondrial toxicity or HIV-related oxidative stress, but could also alter lipid metabolism and promote fat accumulation in the liver. ART, particularly that with nucleoside reverse transcriptase inhibitors (NRTIs), can directly induce mitochondrial toxicity. ${ }^{56,59}$ This is of importance since it is estimated that half of the 35 million people infected with HIV worldwide are on ART. ${ }^{60}$ The specific mechanisms by which NRTIs induce mitochondrial toxicity are not entirely clear and differ from drug to drug. ${ }^{61}$ However, most NRTIs inhibit pol-gamma, a DNA polymerase critical for the replication of mitochondrial DNA. ${ }^{59}$ This inhibition leads to mitochondrial dysfunction due to DNA depletion and microvesicular steatosis. ${ }^{58}$

Other mechanisms unrelated to mitochondrial DNA have been proposed. Some NRTIs, such as stavudine (d4T), can inhibit mitochondrial RNA in cell lines. For d4T, this finding is likely related to its ability to induce stress on the mitochondrial RNA polymerase, which may occur in addition to induction of mitochondrial DNA damage. ${ }^{62}$ Zidovudine (AZT) inhibits the mitochondrial adenylate kinase and adenosine nucleotide translocator in isolated mitochondria, both events leading to mitochondrial dysfunction. ${ }^{61}$ The majority of studies related to ART and mechanisms of mitochondrial toxicity have been performed in vitro, and the most common indicator for toxicity is measurement of mitochondrial DNA that, although generally accepted, is a rather controversial measurement of mitochondrial dysfunction. ${ }^{63}$

Overall, NRTI-containing regimens present the highest risk for liver fibrosis, and no ART regimen is considered completely safe. ${ }^{60}$ This is of importance, since although most ART regimens applied in the developed world do not include NRTIs, the great majority of HIV-infected patients are treated in the developing world (such as Africa) with regimens in which NRTIs are part of most first line therapies for ART. ${ }^{64,65}$ Interestingly, a recent study suggested that exposure to didanosine (even if later replaced) is a risk factor for liver fibrosis in $\mathrm{HIV}$, although the mechanisms behind this effect are unclear. ${ }^{66} \mathrm{HIV}$-infected patients receiving protease inhibitors frequently experience lipodystrophy (known as HALS as described above). Protease inhibitors can decrease peripheral lipolysis through inhibition of GLUT-4 activity, thereby increasing adipocyte size. ${ }^{67}$ These hypertrophic adipocytes in the peripheral tissue and abdomen lose functional activity and become resistant to insulin. Consequently, insulin-resistant adipocytes secrete less adiponectin, which in turn increases body fat, worsening deposition of liver fat and fibrosis. ${ }^{68}$ Newer protease inhibitors exhibit less incidence of HALS; however, data is emerging on the direct role of HIV-mediated inflammation promoting endothelial lipase and phospholipase A2 and thus inducing HALS. ${ }^{69,70}$

Finally, some HIV-infected populations have a higher alcohol consumption behavior. ${ }^{71}$ It is well known that alcohol is metabolized in the liver, with acetaldehyde promoting glutathione depletion and lipid peroxidation, which leads to mitochondrial damage exacerbating hepatic steatosis and fibrosis. ${ }^{72}$ Recent data suggests that alcohol binge drinking can increase bacterial translocation from the gut microbiome. ${ }^{73}$ This effect could be exacerbated in HIV-infected individuals, leading to a higher degree of alcoholic steatohepatitis and liver fibrosis. Nonetheless, it remains unclear whether the overall effects of alcohol consumption are accentuated or worsened during HIV infection. ${ }^{74,75}$

\section{Co-infection with viral hepatitis}

Approximately 5 million persons are co-infected with HIV and HCV worldwide. ${ }^{76}$ Patients co-infected with HIV and HCV experience a more rapid progression to liver fibrosis (Table 1 ) and develop hepatocellular carcinoma at a younger age than those infected with either virus alone (52 vs. 64 years, respectively) ${ }^{77-79}$ While the exact mechanisms for advanced fibrosis in co-infection are not entirely clear, several studies have shed light on this interaction. Both HIV and HCV infection can induce hepatocyte apoptosis via activation of the TRAIL receptors, and increase TRAIL expression by hepatocytes. ${ }^{32,80} \mathrm{HIV}$ infection renders hepatocytes sensitive to TRAIL with increased TRAIL-R2 expression. It is possible that upon subsequent challenge of the liver with HCV, TRAIL production increases, resulting in hepatocyte death with liver fibrosis. ${ }^{31}$

HCV/HIV co-infected persons also have increased plasma levels of LPS. ${ }^{81,82}$ In these co-infected patients with advanced liver disease, bacterial clearance from the liver is impaired, which may establish an enhanced state of intrahepatic inflammation and create an environment for more rapid progression of liver fibrosis. ${ }^{12,83}$ Moreover, the HIV gp120 protein can enhance HCV-induced regulation of TGF- $\beta$. Besides the profibrinogenic effects described above, TGF- $\beta$ can also increase HCV RNA replication in cell cultures, which is further enhanced by HIV, suggesting that HIV augments liver

Table 1. Studies addressing liver fibrosis progression in HIV/HCV using biopsies

\begin{tabular}{|c|c|c|c|c|}
\hline Name ${ }^{\text {ref }}$ & Year & $\begin{array}{l}\mathrm{N} \text { of } \\
\text { patients }\end{array}$ & Findings & Additional comments \\
\hline Konerman et al. ${ }^{6}$ & 2014 & 282 & Accelerated fibrosis progression & $\begin{array}{l}\text { Association with AST/ALT and } \\
\text { fibrosis }\end{array}$ \\
\hline Leite et al. ${ }^{79}$ & 2015 & 30 & Accelerated fibrosis progression & $\begin{array}{l}\text { Association with AST/ALT and } \\
\text { fibrosis }\end{array}$ \\
\hline Schmid et al. ${ }^{96}$ & 2015 & $42 *$ & $25 \%$ experienced fibrosis progression & ${ }^{*} \mathrm{~N}$ of patients with 2 liver biopsies \\
\hline Macias et al. ${ }^{83}$ & 2009 & 135 & $\begin{array}{l}\text { Fibrosis progression; Decreased } \\
\text { progression by ART }\end{array}$ & $\begin{array}{l}\text { Interval between biopsies of } 3.2 \\
\text { years }\end{array}$ \\
\hline Schiavini et al. ${ }^{78}$ & 2011 & 58 & Reduced fibrosis progression with ART & $\begin{array}{l}\text { Correlation between fibrosis and } \\
\text { CD4 count }\end{array}$ \\
\hline Sterling et $a{ }^{97}$ & 2010 & $59 *$ & $\begin{array}{l}\text { Similar rate of fibrosis in } \mathrm{HIV} / \mathrm{HCV} \text { than in } \\
\mathrm{HCV}\end{array}$ & $\begin{array}{l}\text { *59 HIV/HCV vs } 59 \text { HCV; } 5 \text {-year } \\
\text { interval }\end{array}$ \\
\hline
\end{tabular}


damage pathways already established by HCV as well as increases HCV RNA replication. ${ }^{84,85}$ With the arrival of new direct acting antiviral (DAA) medications for treatment of $\mathrm{HCV}$, it is likely that the fibrinogenic effects related to active $\mathrm{HCV}$ replication in HIV-infected patients will be dramatically reduced. ${ }^{86}$

Interestingly, despite the increasing understanding of mechanisms by which HCV and HIV interact to cause liver disease, relatively little is known about viral interactions between HBV and HIV. Moreover, most studies about the natural history of HBV in HIV have been conducted in areas of the world where HBV is acquired in adulthood, leading to the question of whether the effects of HIV are the same when HIV is acquired following establishment of chronic HBV, as occurs in countries with high HBV endemicity.

Approximately $8 \%$ of HIV-infected patients are co-infected with HBV, although this rate varies depending on the geographic location. Similar to its interaction with HCV, HIV accelerates the course of liver disease caused by HBV. ${ }^{87,88}$ Moreover, HBV patients co-infected with HIV are less likely to become negative for hepatitis $B$ e antigen, increasing the risk of active hepatitis and liver damage compared to cases of HBV mono-infection. ${ }^{89}$ LPS levels are elevated in patients co-infected with HBV and HIV, likely predisposing to similar intrahepatic inflammation and fibrosis as seen with $\mathrm{HIV} / \mathrm{HCV}$ co-infection. ${ }^{90}$ Interestingly, HBV has been shown to suppress TLR-mediated innate immune responses, eliciting activation and expression of pro-inflammatory cytokines. ${ }^{91}$ This could have implications in the development of liver fibrosis during HIV co-infection, but to date there are no studies addressing this issue.

TGF- $\beta$ expression has also been associated to liver fibrosis in HBV-infected patients, but a role in HIV coinfected patients has not been demonstrated. ${ }^{92}$ Differing from HCV/HIV co-infections, liver fibrosis mediated through apoptosis-related receptors does not seem to play a major role in HBV/HIV co-infection. It has also been hypothesized that HIV modulation of the HBV-specific immune response alters the hepatic cytokine environment, affecting liver fibrosis and disease progression, but this hypothesis has not been thoroughly tested. ${ }^{93}$

\section{Conclusions}

With the introduction of ART, a dramatic reduction in HIVrelated morbidity and mortality has been observed. However, despite these advances, HIV-infected patients remain at high risk for liver-related disease and mortality. ${ }^{94-97}$ The pathophysiology of liver fibrosis in patients with HIV is a multifactorial process. Control of HIV replication will likely mitigate the effects of the virus in liver fibrosis, but mitochondrial toxicity and insulin resistance from the treatment may negatively impact the hepatic environment. In addition, ROS from metabolic disturbances such as alcohol consumption, NAFLD, HBV and $\mathrm{HCV}$ infection play a major role in the balance between immune response and fibrosis. Key challenges facing researchers today are to translate our understanding of HIVmediated liver damage into the development of anti-fibrotic therapies and to identify biomarkers that could allow for individualized approaches to therapy.

\section{Acknowledgments}

Funded in part by the Virgo consortium, the Dutch government (project number FES0908 to AB), the American College of Gastroenterology (CRA to JDD), and the United States' National Institutes of Health (grant AI096925 to PRB).

\section{Conflict of interest}

None

\section{Author contributions}

Interpreted studies, wrote majority of the manuscript (JDD), provided guidance in writing, revised the article for important intellectual content (PRB), wrote part of the manuscript, edited content, interpreted studies $(A B)$.

\section{References}

[1] Limketkai BN, Mehta SH, Sutcliffe CG, Higgins YM, Torbenson MS, Brinkley $\mathrm{SC}$, et al. Relationship of liver disease stage and antiviral therapy with liverrelated events and death in adults coinfected with HIV/HCV. JAMA 2012;308: 370-378. doi: 10.1001/jama.2012.7844.

[2] Pacheco YM, Jarrin I, Rosado I, Campins AA, Berenguer J, Iribarren JA, et al. Increased risk of non-AIDS-related events in HIV subjects with persistent low CD4 counts despite CART in the CoRIS cohort. Antiviral Res 2015;117:69-74. doi: 10.1016/j.antiviral.2015.03.002.

[3] Smith CJ, Ryom L, Weber R, Morlat P, Pradier C, Reiss P, et al. Trends in underlying causes of death in people with HIV from 1999 to 2011 (D:A:D): a multicohort collaboration. Lancet 2014;384:241-248. doi: 10.1016/S0140-6736 (14)60604-8.

[4] Han SH, Kim SU, Kim CO, Jeong SJ, Park JY, Choi JY, et al. Abnormal liver stiffness assessed using transient elastography (Fibroscan ${ }^{\circledR}$ ) in HIV-infected patients without $\mathrm{HBV} / \mathrm{HCV}$ coinfection receiving combined antiretroviral treatment. PLoS One 2013;8:e52720. doi: 10.1371/journal.pone.0052720.

[5] Redd AD, Wendel SK, Grabowski MK, Ocama P, Kiggundu V, Bbosa F, et al. Liver stiffness is associated with monocyte activation in HIV-infected Ugandans without viral hepatitis. AIDS Res Hum Retroviruses 2013;29: 1026-1030. doi: 10.1089/AID.2013.0004.

[6] Konerman MA, Mehta SH, Sutcliffe CG, Vu T, Higgins Y, Torbenson MS, et al. Fibrosis progression in human immunodeficiency virus/hepatitis $\mathrm{C}$ virus coinfected adults: prospective analysis of 435 liver biopsy pairs. Hepatology 2014;59:767-775. doi: 10.1002/hep.26741.

[7] Kleiner DE, Brunt EM. Nonalcoholic fatty liver disease: pathologic patterns and biopsy evaluation in clinical research. Semin Liver Dis 2012;32:3-13. doi: $10.1055 / \mathrm{s}-0032-1306421$.

[8] Trautwein C, Friedman SL, Schuppan D, Pinzani M. Hepatic fibrosis: Concept to treatment. J Hepatol 2015;62:S15-S24. doi: 10.1016/j.jhep.2015.02. 039.

[9] Singh S, Allen AM, Wang Z, Prokop LJ, Murad MH, Loomba R. Fibrosis progression in nonalcoholic fatty liver vs nonalcoholic steatohepatitis: a systematic review and meta-analysis of paired-biopsy studies. Clin Gastroenterol Hepatol 2015;13:643-654.e649. doi: 10.1016/j.cgh.2014.04.014.

[10] Hernandez-Gea V, Friedman SL. Pathogenesis of liver fibrosis. Annu Rev Pathol 2011;6:425-456. doi: 10.1146/annurev-pathol-011110-130246.

[11] Blackard JT, Sherman KE. HCV/ HIV co-infection: time to re-evaluate the role of HIV in the liver? J Viral Hepat 2008;15:323-330. doi: $10.1111 / \mathrm{j} .1365-$ 2893.2008.00970.x.

[12] Lin W, Weinberg EM, Chung RT. Pathogenesis of accelerated fibrosis in HIV/HCV co-infection. J Infect Dis 2013;207 Suppl 1:S13-S18. doi: 10.1093/ infdis/jis926.

[13] May MT, Gompels M, Delpech V, Porter K, Orkin C, Kegg S, et al. Impact on life expectancy of HIV-1 positive individuals of CD4+ cell count and viral load response to antiretroviral therapy. AIDS 2014;28:1193-1202. doi: 10. 1097/QAD.0000000000000243.

[14] Lemoine M, Serfaty L, Capeau J. From nonalcoholic fatty liver to nonalcoholic steatohepatitis and cirrhosis in HIV-infected patients: diagnosis and management. Curr Opin Infect Dis 2012;25:10-16. doi: 10.1097/QCO. 0b013e32834ef599.

[15] Joshi D, O'Grady J, Dieterich D, Gazzard B, Agarwal K. Increasing burden of liver disease in patients with HIV infection. Lancet 2011;377:1198-1209. doi: 10.1016/S0140-6736(10)62001-6. 
[16] Vodkin I, Valasek MA, Bettencourt R, Cachay E, Loomba R. Clinical, biochemical and histological differences between HIV-associated NAFLD and primary NAFLD: a case-control study. Aliment Pharmacol Ther 2015;41:368-378. doi: $10.1111 /$ apt.13052.

[17] Mohammed SS, Aghdassi E, Salit IE, Avand G, Sherman M, Guindi M, et al. HIV-positive patients with nonalcoholic fatty liver disease have a lower body mass index and are more physically active than HIV-negative patients. J Acquir Immune Defic Syndr 2007;45:432-438. doi: 10.1097/QAI. 0b013e318074efe3.

[18] Guaraldi G, Squillace N, Stentarelli C, Orlando G, D'Amico R, Ligabue G, et al. Nonalcoholic fatty liver disease in HIV-infected patients referred to a metabolic clinic: prevalence, characteristics, and predictors. Clin Infect Dis 2008; 47:250-257. doi: 10.1086/589294.

[19] Debes JD, Marianelli LG, Frassone N, Ballari E, Castrillon ME, Zhang L, et al. Fatty liver in hispanics with HIV. AIDS Res Hum Retroviruses 2016;32: 515-516. doi: 10.1089/AID.2016.0020.

[20] Paruthi J, Gill N, Mantzoros CS. Adipokines in the HIV/HAART-associated lipodystrophy syndrome. Metabolism 2013;62:1199-1205. doi: 10.1016/j. metabol.2013.04.014.

[21] Mastroianni CM, Lichtner M, Mascia C, Zuccalà P, Vullo V. Molecular mechanisms of liver fibrosis in HIV/HCV coinfection. Int J Mol Sci 2014;15:91849208. doi: 10.3390/ijms15069184.

[22] Paradis V, Perlemuter G, Bonvoust F, Dargere D, Parfait B, Vidaud M, et al. High glucose and hyperinsulinemia stimulate connective tissue growth factor expression: a potential mechanism involved in progression to fibrosis in nonalcoholic steatohepatitis. Hepatology 2001;34:738-744. doi: 10.1053/jhep. 2001.28055.

[23] Massanella M, Fromentin R, Chomont N. Residual inflammation and viral reservoirs: alliance against an HIV cure. Curr Opin HIV AIDS 2016;11: 234-241. doi: 10.1097/COH.0000000000000230.

[24] Kiselinova M, Geretti AM, Malatinkova E, Vervisch K, Beloukas A, Messiaen P, et al. HIV-1 RNA and HIV-1 DNA persistence during suppressive ART with PI-based or nevirapine-based regimens. J Antimicrob Chemother 2015;70: 3311-3316. doi: 10.1093/jac/dkv250.

[25] Vlahakis SR, Villasis-Keever A, Gomez TS, Bren GD, Paya CV. Human immunodeficiency virus-induced apoptosis of human hepatocytes via CXCR4. J Infect Dis 2003;188:1455-1460. doi: $10.1086 / 379738$.

[26] Nomiyama H, Hieshima K, Nakayama T, Sakaguchi T, Fujisawa R, Tanase S, et al. Human CC chemokine liver-expressed chemokine/CCL16 is a functional ligand for CCR1, CCR2 and CCR5, and constitutively expressed by hepatocytes. Int Immunol 2001;13:1021-1029.

[27] Lin W, Wu G, Li S, Weinberg EM, Kumthip K, Peng LF, et al. HIV and HCV cooperatively promote hepatic fibrogenesis via induction of reactive oxygen species and NFkappaB. J Biol Chem 2011;286:2665-2674. doi: 10. $1074 /$ jbc.M110.168286.

[28] Tuyama AC, Hong F, Saiman Y, Wang C, Ozkok D, Mosoian A, et al. Human immunodeficiency virus (HIV)-1 infects human hepatic stellate cells and promotes collagen I and monocyte chemoattractant protein-1 expression: implications for the pathogenesis of HIV/hepatitis $C$ virus-induced liver fibrosis. Hepatology 2010;52:612-622. doi: 10.1002/hep.23679.

[29] Gupta D, Rani M, Khan N, Jameel S. HIV-1 infected peripheral blood mononuclear cells modulate the fibrogenic activity of hepatic stellate cells through secreted TGF- $\beta$ and JNK signaling. PLoS One 2014;9:e91569. doi: 10.1371/ journal.pone.0091569.

[30] Bruno R, Galastri S, Sacchi P, Cima S, Caligiuri A, DeFranco R, et al. gp120 modulates the biology of human hepatic stellate cells: a link between HIV infection and liver fibrogenesis. Gut 2010;59:513-520. doi: 10.1136/gut. 2008.163287.

[31] Rizza SA, Challagundla KB, Natesampillai S, Bren GD, Sykora J, Walczak H, etal. TRAIL dependent fratricidal killing of gp120 primed hepatocytes by HCV core expressing hepatocytes. PLoS One 2011;6:e27171. doi: 10.1371/journal. pone. 0027171 .

[32] Brost S, Zimmermann A, Koschny R, Sykora J, Stremmel W, Schirmacher P, et al. Hepatocyte expression of TRAIL pathway regulators correlates with histopathological and clinical parameters in chronic HCV infection. Pathol Res Pract 2014;210:83-91. doi: 10.1016/j.prp.2013.10.005.

[33] Housset C, Lamas E, Bréchot C. Detection of HIV1 RNA and p24 antigen in HIV1-infected human liver. Res Virol 1990;141:153-159.

[34] Baffy G. Kupffer cells in non-alcoholic fatty liver disease: the emerging view. J Hepatol 2009;51:212-223. doi: 10.1016/j.jhep.2009.03.008.

[35] Patel P, Khan N, Rani M, Gupta D, Jameel S. The expression of HIV-1 Vpu in monocytes causes increased secretion of TGF- $\beta$ that activates profibrogenic genes in hepatic stellate cells. PLoS One 2014;9:e88934. doi: 10.1371/ journal.pone.0088934.

[36] Page EE, Nelson M, Kelleher P. HIV and hepatitis C coinfection: pathogenesis and microbial translocation. Curr Opin HIV AIDS 2011;6:472-477. doi: 10. 1097/COH.0b013e32834bbc71.

[37] Foster RG, Golden-Mason L, Rutebemberwa A, Rosen HR. Interleukin (IL)-17/ IL-22-producing T cells enriched within the liver of patients with chronic hep- atitis C viral (HCV) infection. Dig Dis Sci 2012;57:381-389. doi: 10.1007/ s10620-011-1997-z.

[38] Macek Jilkova Z, Afzal S, Marche H, Decaens T, Sturm N, Jouvin-Marche E, et al. Progression of fibrosis in patients with chronic viral hepatitis is associated with IL-17(+) neutrophils. Liver Int 2016;36:1116-1124. doi: 10. 1111/liv.13060.

[39] Barrett L, Trehanpati N, Poonia S, Daigh L, Sarin SK, Masur H, et al. Hepatic compartmentalization of exhausted and regulatory cells in HIV/HCV-coinfected patients. J Viral Hepat 2015;22:281-288. doi: 10.1111/jvh.12291.

[40] Vali B, Yue FY, Jones RB, Sheth PM, Kaul R, Betts MR, et al. HIV-specific T-cells accumulate in the liver in HCV/HIV co-infection. PLoS One 2008;3: e3454. doi: 10.1371/journal.pone.0003454.

[41] Sandler NG, Douek DC. Microbial translocation in HIV infection: causes, consequences and treatment opportunities. Nat Rev Microbiol 2012;10: 655-666. doi: 10.1038/nrmicro2848.

[42] Brenchley JM, Price DA, Schacker TW, Asher TE, Silvestri G, Rao S, et al. Microbial translocation is a cause of systemic immune activation in chronic HIV infection. Nat Med 2006;12:1365-1371. doi: 10.1038/nm1511.

[43] Marchetti G, Tincati C, Silvestri G. Microbial translocation in the pathogenesis of HIV infection and AIDS. Clin Microbiol Rev 2013;26:2-18. doi: 10.1128/ CMR.00050-12.

[44] Mehandru S, Poles MA, Tenner-Racz K, Horowitz A, Hurley A, Hogan C, et al. Primary HIV-1 infection is associated with preferential depletion of CD4+ T lymphocytes from effector sites in the gastrointestinal tract. J Exp Med 2004; 200:761-770. doi: 10.1084/jem.20041196.

[45] Klatt NR, Funderburg NT, Brenchley JM. Microbial translocation, immune activation, and HIV disease. Trends Microbiol 2013;21:6-13. doi: 10.1016/j. tim.2012.09.001.

[46] Corbitt N, Kimura S, Isse K, Specht S, Chedwick L, Rosborough BR, et al. Gut bacteria drive Kupffer cell expansion via MAMP-mediated ICAM-1 induction on sinusoidal endothelium and influence preservation-reperfusion injury after orthotopic liver transplantation. Am J Pathol 2013;182:180-191. doi: 10.1016/j.ajpath.2012.09.010.

[47] Schnabl B, Brenner DA. Interactions between the intestinal microbiome and liver diseases. Gastroenterology 2014;146:1513-1524. doi: 10.1053/j. gastro.2014.01.020.

[48] Hufert FT, Schmitz J, Schreiber M, Schmitz H, Rácz P, von Laer DD. Human Kupffer cells infected with HIV-1 in vivo. J Acquir Immune Defic Syndr 1993; 6:772-777.

[49] Balagopal A, Ray SC, De Oca RM, Sutcliffe CG, Vivekanandan P, Higgins Y, et al. Kupffer cells are depleted with HIV immunodeficiency and partially recovered with antiretroviral immune reconstitution. AIDS 2009;23:23972404. doi: 10.1097/QAD.0b013e3283324344.

[50] Seki E, De Minicis S, Osterreicher CH, Kluwe J, Osawa Y, Brenner DA, et al. TLR4 enhances TGF-beta signaling and hepatic fibrosis. Nat Med 2007;13: 1324-1332. doi: $10.1038 / \mathrm{nm} 1663$.

[51] Castilla A, Prieto J, Fausto N. Transforming growth factors beta 1 and alpha in chronic liver disease. Effects of interferon alfa therapy. N Engl J Med 1991; 324:933-940. doi: 10.1056/NEJM199104043241401.

[52] Kanzler S, Baumann M, Schirmacher P, Dries V, Bayer E, Gerken G, et al. Prediction of progressive liver fibrosis in hepatitis $C$ infection by serum and tissue levels of transforming growth factor-beta. J Viral Hepat 2001;8: 430-437.

[53] Li MO, Wan YY, Sanjabi S, Robertson AK, Flavell RA. Transforming growth factor-beta regulation of immune responses. Annu Rev Immunol 2006;24: 99-146. doi: 10.1146/annurev.immunol.24.021605.090737.

[54] Balagopal A, Philp FH, Astemborski J, Block TM, Mehta A, Long R, et al. Human immunodeficiency virus-related microbial translocation and progression of hepatitis C. Gastroenterology 2008;135:226-233. doi: 10.1053/j. gastro.2008.03.022.

[55] Morse CG, Voss JG, Rakocevic G, McLaughlin M, Vinton CL, Huber C, et al. HIV infection and antiretroviral therapy have divergent effects on mitochondria in adipose tissue. J Infect Dis 2012;205:1778-1787. doi: 10.1093/infdis/jis101.

[56] Maagaard A, Holberg-Petersen M, Løvgården G, Holm M, Pettersen FO, Kvale D. Distinct mechanisms for mitochondrial DNA loss in T and B lymphocytes from HIV-infected patients exposed to nucleoside reverse-transcriptase inhibitors and those naive to antiretroviral treatment. J Infect Dis 2008; 198:1474-1481. doi: 10.1086/592713.

[57] Douek DC, Picker L], Koup RA. T cell dynamics in HIV-1 infection. Annu Rev Immunol 2003;21:265-304. doi: 10.1146/annurev.immunol.21.120601. 141053.

[58] Begriche K, Massart J, Robin MA, Bonnet F, Fromenty B. Mitochondrial adaptations and dysfunctions in nonalcoholic fatty liver disease. Hepatology 2013;58:1497-1507. doi: 10.1002/hep.26226.

[59] Pérez-Matute P, Pérez-Martínez L, Blanco JR, Oteo JA. Role of mitochondria in HIV infection and associated metabolic disorders: focus on nonalcoholic fatty liver disease and lipodystrophy syndrome. Oxid Med Cell Longev 2013;2013: 493413. doi: 10.1155/2013/493413. 
[60] Gallant JE, Mehta SH, Sugarman J. Universal antiretroviral therapy for HIV infection: should US treatment guidelines be applied to resource-limited settings? Clin Infect Dis 2013;57:884-887. doi: 10.1093/cid/cit382.

[61] Feeney ER, Mallon PW. Impact of mitochondrial toxicity of HIV-1 antiretroviral drugs on lipodystrophy and metabolic dysregulation. Curr Pharm Des 2010;16:3339-3351.

[62] Galluzzi L, Pinti M, Troiano L, Prada N, Nasi M, Ferraresi R, et al. Changes in mitochondrial RNA production in cells treated with nucleoside analogues. Antivir Ther 2005;10:191-195.

[63] Apostolova N, Blas-García A, Esplugues JV. Mitochondrial interference by anti-HIV drugs: mechanisms beyond Pol- $\gamma$ inhibition. Trends Pharmacol Sc 2011;32:715-725. doi: 10.1016/j.tips.2011.07.007.

[64] Boender TS, Sigaloff KC, McMahon JH, Kiertiburanakul S, Jordan MR, Barcarolo J, et al. Long-term virological outcomes of first-line antiretroviral therapy for HIV-1 in low- and middle-income countries: a systematic review and meta-analysis. Clin Infect Dis 2015;61:1453-1461. doi: 10.1093/cid/ civ556.

[65] Tang MW, Rhee SY, Bertagnolio S, Ford N, Holmes S, Sigaloff KC, et al. Nucleoside reverse transcriptase inhibitor resistance mutations associated with first-line stavudine-containing antiretroviral therapy: programmatic implications for countries phasing out stavudine. J Infect Dis 2013;207 Suppl 2:S70-S77. doi: 10.1093/infdis/jit114.

[66] Kooij KW, Wit FW, van Zoest RA, Schouten J, Kootstra NA, van Vugt M, et al. Liver fibrosis in HIV-infected individuals on long-term antiretroviral therapy: associated with immune activation, immunodeficiency and prior use of didanosine. AIDS 2016;30:1771-1780. doi: 10.1097/QAD.0000000000001119.

[67] Carper MJ, Cade WT, Cam M, Zhang S, Shalev A, Yarasheski KE, et al. HIVprotease inhibitors induce expression of suppressor of cytokine signaling-1 in insulin-sensitive tissues and promote insulin resistance and type 2 diabetes mellitus. Am J Physiol Endocrinol Metab 2008;294:E558-567. doi: 10.1152/ ajpendo.00167.2007.

[68] Maximos M, Bril F, Portillo Sanchez P, Lomonaco R, Orsak B, Biernacki D, et al. The role of liver fat and insulin resistance as determinants of plasma aminotransferase elevation in nonalcoholic fatty liver disease. Hepatology 2015 ; 61:153-160. doi: 10.1002/hep.27395.

[69] Baker J, Ayenew W, Quick H, Hullsiek KH, Tracy R, Henry K, et al. Highdensity lipoprotein particles and markers of inflammation and thrombotic activity in patients with untreated HIV infection. J Infect Dis 2010;201 285-292. doi: $10.1086 / 649560$.

[70] da Cunha J, Maselli LM, Stern AC, Spada C, Bydlowski SP. Impact of antiretroviral therapy on lipid metabolism of human immunodeficiency virusinfected patients: Old and new drugs. World J Virol 2015;4:56-77. doi: 10 5501/wjv.v4.i2.56.

[71] Justice AC, Lasky E, McGinnis KA, Skanderson M, Conigliaro J, Fultz SL, et al. Medical disease and alcohol use among veterans with human immunodeficiency infection: A comparison of disease measurement strategies. Med Care 2006;44:S52-S60. doi: 10.1097/01.mlr.0000228003.08925.8c.

[72] Farfán Labonne BE, Gutiérrez M, Gómez-Quiroz LE, Konigsberg Fainstein M, Bucio L, Souza V, et al. Acetaldehyde-induced mitochondrial dysfunction sensitizes hepatocytes to oxidative damage. Cell Biol Toxicol 2009;25:599-609. doi: 10.1007/s10565-008-9115-5.

[73] Bala S, Marcos M, Gattu A, Catalano D, Szabo G. Acute binge drinking increases serum endotoxin and bacterial DNA levels in healthy individuals. PLoS One 2014;9:e96864. doi: 10.1371/journal.pone.0096864.

[74] Fuster D, Tsui JI, Cheng DM, Quinn EK, Bridden C, Nunes D, et al. Impact of lifetime alcohol use on liver fibrosis in a population of HIV-infected patients with and without hepatitis C coinfection. Alcohol Clin Exp Res 2013;37:15271535. doi: 10.1111/acer.12129.

[75] Bilal U, Lau B, Lazo M, McCaul ME, Hutton HE, Sulkowski MS, et al. Interaction between alcohol consumption patterns, antiretroviral therapy type, and liver fibrosis in persons living with HIV. AIDS Patient Care STDS 2016;30:200207. doi: 10.1089/apc.2016.0010.

[76] Sherman KE, Thomas DL, Chung RT. Human immunodeficiency virus and liver disease forum 2010: conference proceedings. Hepatology 2011;54: 2245-2253. doi: 10.1002/hep.24651.

[77] Chen JY, Feeney ER, Chung RT. HCV and HIV co-infection: mechanisms and management. Nat Rev Gastroenterol Hepatol 2014;11:362-371. doi: 10. 1038/nrgastro.2014.17.
[78] Schiavini M, Angeli E, Mainini A, Uberti-Foppa C, Zerbi $P$, Sagnelli $C$, et al. Fibrosis progression in paired liver biopsies from HIV/HCV co-infected patients. Hepat Mon 2011;11:525-531.

[79] Leite AG, Duarte MI, Mendes-Correa MC. Fibrosis progression in paired liver biopsies from HIV/HCV-coinfected patients without prior treatment of hepatitis C. J Int Assoc Provid AIDS Care 2015;14:463-468. doi: 10.1177/ 2325957415587571.

[80] Macias J, Japón MA, Sáez C, Palacios RB, Mira JA, García-García JA, et al. Increased hepatocyte fas expression and apoptosis in HIV and hepatitis C virus coinfection. J Infect Dis 2005;192:1566-1576. doi: 10.1086/491736.

[81] Sandler NG, Koh C, Roque A, Eccleston JL, Siegel RB, Demino M, et al. Host response to translocated microbial products predicts outcomes of patients with HBV or HCV infection. Gastroenterology 2011;141:1220-1230, 1230. e1221-1223. doi: 10.1053/j.gastro.2011.06.063.

[82] French AL, Evans CT, Agniel DM, Cohen MH, Peters M, Landay AL, et al. Microbial translocation and liver disease progression in women coinfected with HIV and hepatitis C virus. J Infect Dis 2013;208:679-689. doi: 10.1093/infdis/ jit225.

[83] Macías J, Berenguer J, Japón MA, Girón JA, Rivero A, López-Cortés LF, et al. Fast fibrosis progression between repeated liver biopsies in patients coinfected with human immunodeficiency virus/hepatitis C virus. Hepatology 2009;50:1056-1063. doi: 10.1002/hep.23136.

[84] Presser LD, Haskett A, Waris G. Hepatitis C virus-induced furin and thrombospondin- 1 activate TGF- $\beta 1$ : role of TGF- $\beta 1$ in HCV replication. Virology 2011;412:284-296. doi: 10.1016/j.virol.2010.12.051.

[85] Lin W, Weinberg EM, Tai AW, Peng LF, Brockman MA, Kim KA, et al. HIV increases HCV replication in a TGF-beta1-dependent manner. Gastroenterology $2008 ; 134: 803-811$. doi: 10.1053/j.gastro.2008.01.005.

[86] Rockstroh JK. Optimal therapy of HIV/HCV co-infected patients with direct acting antivirals. Liver Int 2015;35 Suppl 1:51-55. doi: 10.1111/liv.12721.

[87] Soriano V, Poveda E, Vispo E, Barreiro P. Hepatitis B in HIV-infected patients. Clin Liver Dis 2013;17:489-501. doi: 10.1016/j.cld.2013.05.008.

[88] Hoffmann CJ, Thio CL. Clinical implications of HIV and hepatitis B co-infection in Asia and Africa. Lancet Infect Dis 2007;7:402-409. doi: 10.1016/S14733099(07)70135-4.

[89] Gilson RJ, Hawkins AE, Beecham MR, Ross E, Waite J, Briggs M, et al. Interactions between HIV and hepatitis $B$ virus in homosexual men: effects on the natural history of infection. AIDS 1997;11:597-606.

[90] Crane M, Avihingsanon A, Rajasuriar R, Velayudham P, Iser D, Solomon A, et al. Lipopolysaccharide, immune activation, and liver abnormalities in $\mathrm{HIV} /$ hepatitis B virus (HBV)-coinfected individuals receiving HBV-active combination antiretroviral therapy. J Infect Dis 2014;210:745-751. doi: 10.1093/ infdis/jiu119.

[91] Wu J, Meng Z, Jiang M, Pei R, Trippler M, Broering R, et al. Hepatitis B virus suppresses toll-like receptor-mediated innate immune responses in murine parenchymal and nonparenchymal liver cells. Hepatology 2009;49:11321140. doi: 10.1002/hep.22751.

[92] Ming D, Yu X, Guo R, Deng Y, Li J, Lin C, et al. Elevated TGF- $\beta 1 /$ IL-31 pathway is associated with the disease severity of hepatitis $B$ virus-related liver cirrhosis. Viral Immunol 2015;28:209-216. doi: 10.1089/vim.2014.0142.

[93] Thio CL. Hepatitis B and human immunodeficiency virus coinfection. Hepatology 2009;49:S138-S145. doi: 10.1002/hep.22883.

[94] Lo Re V, Kallan MJ, Tate JP, Localio AR, Lim JK, Goetz MB, et al. Hepatic decompensation in antiretroviral-treated patients co-infected with HIV and hepatitis $C$ virus compared with hepatitis $C$ virus-monoinfected patients: a cohort study. Ann Intern Med 2014;160:369-379. doi: 10.7326/M13-1829.

[95] Anderson JP, Tchetgen Tchetgen EJ, Lo Re V 3rd, Tate JP, Williams PL, Seage GR 3rd, et al. Antiretroviral therapy reduces the rate of hepatic decompensation among HIV- and hepatitis $C$ virus-coinfected veterans. Clin Infect Dis 2014;58:719-727. doi: 10.1093/cid/cit779.

[96] Schmid P, Bregenzer A, Huber M, Rauch A, Jochum W, Müllhaupt B, et al. Progression of liver fibrosis in HIV/HCV co-infection: a comparison between non-invasive assessment methods and liver biopsy. PLoS One 2015;10: e0138838. doi: 10.1371/journal.pone.0138838.

[97] Sterling RK, Wegelin JA, Smith PG, Stravitz RT, Luketic VA, Fuchs M, et al. Similar progression of fibrosis between HIV/HCV-infected and HCV-infected patients: Analysis of paired liver biopsy samples. Clin Gastroenterol Hepatol 2010;8:1070-1076. doi: 10.1016/j.cgh.2010.08.004. 